\title{
Perfusion Scintigraphy in the Assessment of Autologous Cell Therapy in Diabetic Patients With Critical Limb Ischemia
}

\author{
A. NEMCOVA ${ }^{1}$, A. JIRKOVSKA ${ }^{1}$, M. DUBSKY ${ }^{1}$, R. BEM ${ }^{1}$, V. FEJFAROVA $^{1}$, \\ V. WOSKOVA ${ }^{1}$, A. PYSNA ${ }^{1}$, M. BUNCOVA ${ }^{2}$ \\ ${ }^{1}$ Diabetes Centre, Institute for Clinical and Experimental Medicine, Prague, Czech Republic, \\ ${ }^{2}$ Department of Nuclear Medicine, Institute for Clinical and Experimental Medicine, Prague, Czech \\ Republic
}

Received January 23, 2018

Accepted February 20, 2018

On-line May 10, 2018

\begin{abstract}
Summary
Perfusion scintigraphy with technetium-99-methoxy-isobutylisonitrile ${ }^{99 m}$ Tc-MIBI) is often used for assessing myocardial function but the number of studies concerning lower limb perfusion is limited. The aim of our study was to assess whether ${ }^{99 m}$ Tc-MIBI was an eligible method for evaluation of the effect of cell therapy on critical limb ischemia (CLI) in diabetic patients. ${ }^{99 \mathrm{~m}}$ Tc-MIBI of calf muscles was performed before and 3 months after autologous cell therapy (ACT) in 24 diabetic patients with CLI. Scintigraphic parameters such as rest count and exercising count after a stress test were defined. These parameters and their ratios were compared between treated and untreated (control) limbs and with changes in transcutaneous oxygen pressure $\left(\mathrm{TCPO}_{2}\right)$ that served as a reference method. The effect of ACT was confirmed by a significant increase in $\mathrm{TCPO}_{2}$ values $(p<0.001)$ at 3 months after ACT. We did not observe any significant changes of scintigraphic parameters both at rest and after stress 3 months after ACT, there were no differences between treated and control limbs and no association with $\mathrm{TcPO}_{2}$ changes. Results of our study showed no significant contribution of ${ }^{99 \mathrm{~m}}$ Tc-MIBI of calf muscles to the assessment of ACT in diabetic patients with CLI over a 3-month follow-up period.
\end{abstract}

\section{Key words}

Perfusion scintigraphy • Critical limb ischemia • Diabetic foot • Autologous cell therapy

\section{Corresponding author}

A. Nemcova, Diabetes Centre, Institute for Clinical and Experimental Medicine, Videnska 1958/9, 14021 Prague 4, Czech Republic. Fax: 00420261362820. E-mail: andrea.nemc@gmail.com

\section{Introduction}

Critical limb ischemia (CLI) is defined as persistent rest pain, ulceration or gangrene attributable to objectively proven peripheral arterial disease (PAD) (Hinchliffe et al. 2016). Peripheral arterial disease and CLI are highly prevalent in patients with diabetes and the diagnosis of CLI portends a high rate of limb loss along with patient mortality (Dua and Lee 2016). Traditionally, the standard methods in the treatment of CLI have been open bypass surgery or endovascular interventions such as percutaneous transluminal angioplasty (PTA) or stenting (Benitez et al. 2014). However, about one third of patients with CLI are not eligible for standard revascularization due to excessive operative risk or unfavorable vascular involvement (Compagna et al. 2015), especially long-segment occlusions and distal arterial disease which is characteristic for diabetic patients (Collinson and Donnelly 2004). Autologous cell therapy (ACT) is a new promising therapeutic modality for these patients with no-option CLI (Fadini et al. 2010, Lawall et al. 2010).

Autologous cell therapy is based on injection of a cell suspension consisting of a heterogeneous progenitor cell population (Aghi and Chiocca 2005) harvested from bone marrow or separated from peripheral blood stimulated by growth factors. Previous studies showed that ACT was safe and effective for achieving therapeutic angiogenesis in diabetic patients with CLI and could obtain better clinical outcomes if injected into the affected lower limb (Liu et al. 2015, Sun et al. 2015). 
While the use of cell-based therapies has produced some positive results, evaluation of the effect of ACT is still difficult. There is a lack of imaging techniques for the assessment of microcirculation; the standard method for evaluating the therapeutic effect in most studies focused on cell therapy in CLI is transcutaneous oxygen pressure $\left(\mathrm{TcPO}_{2}\right)$ measurement (Ai et al. 2016). Ankle-brachial pressure index (ABPI) is only effective in evaluating large vessel obstructions and has decreased sensitivity in the setting of microvascular disease; in addition, ABPI values may be exaggerated in the presence of arterial calcification (Potier et al. 2011). Similarly, digital subtraction angiography provides good anatomic information about the large arteries, but given the usual amount of the contrast medium, it is not sufficient for small collateral vessels. The disadvantage of CT angiography is low-quality visualization of distal parts of foot vessels; in addition, it is strongly influenced by calcifications due to medial sclerosis, especially in diabetic patients (Brownrigg et al. 2015). Likewise, small collateral vessels are below MR angiography resolution (Pomposelli 2010). All the above imaging techniques have some shortcomings in the evaluation of tissue blood perfusion, especially in diabetic patients in an early stage of PAD and without typical clinical symptoms (Li et al. 2017).

Perfusion scintigraphy with technetium-99methoxy-isobutyl-isonitrile $\left({ }^{99 \mathrm{~m}} \mathrm{Tc}-\mathrm{MIBI}\right)$ is a dynamic method widely used for the assessment of myocardial perfusion (Underwood et al. 2004, Gropler et al. 2010, Gaemperli 2014) because of strong ${ }^{99 \mathrm{~m}} \mathrm{Tc}-\mathrm{MIBI}$ affinity to muscle mitochondries. ${ }^{99 \mathrm{~m}}$ Tc-MIBI is accumulated depending on muscle perfusion and mitochondrial uptake activity. Given the clinical effectiveness of myocardial perfusion scintigraphy, we assume that perfusion scintigraphy of calf muscles could be a suitable technique for verifying collateralization and improvement in muscle perfusion after ACT reflecting as it is oxygenation on the cellular level.

The use of ${ }^{99 \mathrm{~m}}$ Tc-MIBI in skeletal muscle perfusion scintigraphy to identify PAD has been assessed in a few studies (Sayman and Urgancioglu 1991, Celen et al. 2000, Kusmierek et al. 2006, Li et al. 2017). Compared with other radionuclides such as ${ }^{201} \mathrm{Tl}$, ${ }^{99 \mathrm{~m}}$ Tc-MIBI has superior imaging and dosimetry characteristics. Being lipophilic, ${ }^{99 \mathrm{~m}} \mathrm{Tc}-\mathrm{MIBI}$ is able to enter skeletal muscle tissue by passive diffusion and remains there for a prolonged period due to binding to intracellular protein. Another difference is that, unlike
${ }^{201} \mathrm{Tl},{ }^{99 \mathrm{~m}} \mathrm{Tc}-\mathrm{MIBI}$ shows no redistribution (Wolfram et al. 2001).

The aims of our study were to assess whether perfusion scintigraphy of calf muscles was an eligible imaging method for evaluation of the effect of ACT on CLI, to define suitable scintigraphic parameters, to compare differences between the limbs and to assess the association with changes in $\mathrm{TcPO}_{2}$, and to compare changes in scintigraphic parameters between calf muscles and myocardium.

\section{Methods}

Rest and stress radionuclide studies of calf muscles with ${ }^{99 \mathrm{~m}} \mathrm{Tc}-\mathrm{MIBI}$ were performed before and 3 months after ACT in 24 patients with diabetic foot and no-option CLI (mean age 66.3 \pm 11.1 years, mean diabetes duration $21.2 \pm 13.9$ years). Inclusion and exclusion criteria for ACT in no-option CLI patients were published in our previous study (Dubsky et al. 2013). The present study was approved by the local ethic committee (Joint Ethics Committee of the Institute for Clinical and Experimental Medicine and Thomayer Hospital), and all patients gave written informed consent.

Presence of CLI was defined by $\mathrm{TcPO}_{2}<$ $30 \mathrm{~mm} \mathrm{Hg}$, objectively proven below-the-knee stenosis or obliteration on the angiogram, non-healing ulcer or ischemic pain in accordance with the Trans-Atlantic Inter-Society Consensus II criteria for CLI (Norgren et al. 2007). Angiographic findings of lower limbs were assessed using the Graziani classification (morphological categorization focused mainly on infrapopliteal lesions applicable for diabetic patients with CLI) (Graziani et al. 2007).

The clinical effect of treatment of ischemia was confirmed by $\mathrm{TcPO}_{2}$ measurement performed by a standardized method on a TCM400 monitor (Radiometer Medical ApS, Aarhus, Denmark) before ACT and at 1, 2 and 3 months after the procedure.

Bone marrow for ACT was harvested from the iliac crest (approximately $250 \mathrm{ml}$ of bone marrow) in the operating theatre; cell suspension was subsequently separated using a Smart PReP2 device (Harvest Technologies Corporation, Plymouth, MA, USA). The final cell suspension of $40-90 \mathrm{ml}$ was injected into the calf and foot muscles of the affected lower limb in a series of about 40 punctures of 1-2 $\mathrm{ml}$ each.

A complex of ${ }^{99 m}$ Tc-MIBI was administered intravenously. Following injection of $4 \mathrm{MBq} / \mathrm{kg}$ 
${ }^{99 m}$ Tc-MIBI, an early whole-body scan (scan speed $10 \mathrm{~cm} / \mathrm{min}$ ) was performed during the rest phase. Afterwards, single photon emission computed tomography combined with CT imaging (SPECT/CT) of calf and foot muscles was performed using an Infinia Hawkeye 4 gamma camera (GE Healthcare, Wisconsin, USA) equipped with a low energy high-resolution collimator and a $128 \times 128$ matrix. Scintigrams were acquired in the posterior projection. The camera was connected to a Xeleris computer (Xeleris, GE Healthcare, USA).

After the rest phase, each subject was asked to move their foot to produce maximal flexion and extension in the ankle joint 60 times or until the onset of symptoms of CLI such as pain or fatigue. At the end of exercise, $\quad 8 \mathrm{MBq} / \mathrm{kg} \quad{ }^{99 \mathrm{~m}}$ Tc-MIBI was injected intravenously. Next, similar to the rest phase, a wholebody scan and SPECT/CT of calf muscles were performed immediately after the stress test.

Rest and stress scintigraphic parameters of each subject were analyzed within the symmetrically selected rectangular region of interest (ROI) covering calf muscles and muscles of the foot over both (treated and untreated) lower limbs. Scintigraphic parameters such as rest count (RC) and exercising count (EC) were measured in two areas; whole calf and foot regarding to background of whole body scan. Rest counts and ECs were compared between the treated and untreated limbs to assess ${ }^{99 \mathrm{~m}}$ Tc-MIBI uptake symmetry.

Perfusion reserve (PR) of exercising calf muscles was calculated using the following formula

$$
\mathrm{PR}=(\mathrm{EC}-\mathrm{RC}) / \mathrm{RC} \times 100[\%]
$$

where EC means count in exercising calf, RC means count in rest calf.

Another parameter for assessing the difference in the exercising muscle and muscle at rest to compare treated (T) and untreated control (C) limbs was set as stress/rest $\left(\mathrm{SR}_{\mathrm{TClimb}}\right)$ ratio

$\mathrm{SR}_{\mathrm{TClimb}}=\frac{\mathrm{T} / \mathrm{C} \text { after ACT after stress } / \mathrm{T} / \mathrm{C} \text { before } \mathrm{ACT} \text { after stress }}{\mathrm{T} / \mathrm{C} \text { after } \mathrm{ACT} \text { at rest } / \mathrm{T} / \mathrm{C} \text { before } \mathrm{ACT} \text { at rest }}$

where $\mathrm{SR}_{\mathrm{TClimb}}>1$ means improved stress test after therapy, $\mathrm{SR}_{\mathrm{TClimb}} \leq 1$ means the same or worsened stress test after therapy.

The ratio assessing only the treated limb after stress and at rest was set as stress/rest (SR) ratio
$\mathrm{SR}=\frac{\mathrm{T} \text { after ACT after stress } / \mathrm{T} \text { after ACT at rest }}{\mathrm{T} \text { before ACT after stress / T before ACT at rest }}$

where $\mathrm{SR}>1$ means improved stress test after therapy, $\mathrm{SR} \leq 1$ means the same or worsened stress test after therapy.

Myocardial perfusion was evaluated together with calf and foot muscles perfusion assessment. Myocardial parameters such as ejection fraction (EF) and summed rest score (SRS) were set up and evaluated by an experienced nuclear specialist. Using SRS, the severity of the perfusion defect was classified as follows: SRS 0-4 (normal), SRS 5-8 (mild ischemia), SRS 9-12 (moderate ischemia) and $\mathrm{SRS}>12$ (severe ischemia).

All data are expressed as mean \pm standard deviation. Statistical significance was analyzed using the Mann-Whitney test and the Wilcoxon pair test. A correlation between scintigraphic parameters and changes in $\mathrm{TcPO}_{2}$ was tested using Spearman's correlation coefficient.

\section{Results}

Baseline characteristics of patients are shown in Table 1. Autologous cells were injected into the lower limb with more severe angiographic and clinical findings.

Table 1. Characteristics of patients.

\begin{tabular}{lc}
\hline Number of patients & 24 \\
Age (years) & $66.3 \pm 11.1$ \\
Gender (M/F) & $21 / 5$ \\
Type 2 diabetes (\%) & 84.6 \\
Diabetes duration (years) & $21.2 \pm 13.9$ \\
Glycated hemoglobin (mmol/mol) & $57.8 \pm 11.5$ \\
TcPO ${ }_{2}$ before cell therapy (mm Hg) & $16.8 \pm 10.6$ \\
Angiographic findings - Graziani & $5.4 \pm 0.9$ \\
classification (mean \pm SD) & 53.8 \\
Ischemic heart disease (\%) & 26.9 \\
Chronic renal failure- dialysis (\%) & 92.3 \\
Hypertension (\%) & 57.7 \\
Smoking (\%) & \\
\hline
\end{tabular}

The effect of ACT was confirmed by a significant increase in $\mathrm{TcPO}_{2}$ values from baseline $16.8 \pm 10.6$ to $38.4 \pm 11.1 \mathrm{~mm} \mathrm{Hg}(\mathrm{p}<0.001)$ at 3 months after cell therapy (Fig. 1). 


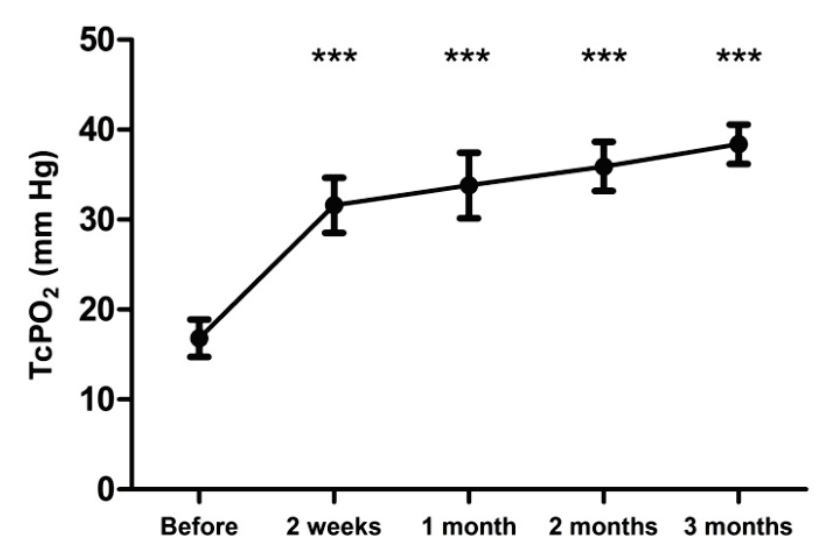

Fig. 1. Changes of $\mathrm{TcPO}_{2}$ after cell therapy. $\mathrm{TCPO}_{2}$ values significantly increase at all intervals $(* * * p<0.001)$.

Rest counts and ECs did not differ significantly between treated vs. untreated limbs before and at 3 months after ACT (Table 2). We did not document any significant differences between treated and untreated limbs before and after therapy; there was no asymmetry in lower limb perfusion.

Mean perfusion reserve of the treated limb was without a significant change before and after ACT (268.4 \pm 77.8 and $258.6 \pm 77.9 \%$, respectively; NS); with 11 patients showing mild improvement, 1 patient with no change and 12 patients some worsening. Similarly, mean perfusion reserve of the control limb was without a significant change $(257.3 \pm 81.6$ and $275.1 \pm 84.3 \%$, respectively; NS).

Mean $\mathrm{SR}_{\mathrm{TClimb}}$ was $1.49 \pm 1.79$; while 12 patients improved, another 12 showed either no change or worsened.

Mean SR was $1.07 \pm 0.48 ; 12$ patients improved and 12 patients were without a significant change or worsened.

No significant correlation between $\mathrm{TcPO}_{2}$ changes and any of the followed perfusion scintigraphic parameters after ACT was found.

Myocardial parameters: There was no significant change in mean SRS before and after ACT (5.7 \pm 8.5 and $4.5 \pm 6.7$, respectively). Also mean EF values did not differ significantly before and after ACT $(56 \pm 18.3 \%$ and $56.8 \pm 17.7 \%$, respectively; NS).

Table 2. Comparison of rest count (RCs) and exercising count (ECS) in treated and control limbs before and after ACT.

\begin{tabular}{|c|c|c|c|c|c|c|}
\hline \multirow{2}{*}{ Limb } & \multicolumn{2}{|c|}{ Mean RCs } & \multicolumn{4}{|c|}{ Mean ECs } \\
\hline & Before ACT & After ACT & & Before ACT & After ACT & \\
\hline \multirow[t]{2}{*}{ Treated (T) } & $31680.9 \pm 10328.1$ & $28567.9 \pm 6955.7$ & NS & $112120.0 \pm 33026.3$ & $104347.7 \pm 36939.9$ & NS \\
\hline & \multicolumn{2}{|c|}{ PR before ACT (\%) } & \multicolumn{3}{|c|}{ PR after ACT (\%) } & NS \\
\hline \multirow[t]{3}{*}{ Control (C) } & $31009.4 \pm 9747.7$ & $29370.7 \pm 9670.8$ & NS & $110095.0 \pm 38490.9$ & $109949.3 \pm 44929.1$ & NS \\
\hline & \multicolumn{2}{|c|}{ PR before ACT $(\%)$} & & \multicolumn{2}{|c|}{ PR after ACT (\%) } & NS \\
\hline & \multicolumn{2}{|c|}{$257.3 \pm 81.6$} & & \multicolumn{3}{|c|}{$275.1 \pm 84.3$} \\
\hline $\begin{array}{l}\text { Difference between } \\
T \text { and } C\end{array}$ & 671.5 & -802.8 & NS & 2025.0 & -5601.6 & NS \\
\hline
\end{tabular}

Data are expressed as mean \pm SD. ACT, autologous cell therapy; PR, perfusion reserve; NS, non-significant.

\section{Discussion}

Results of our study showed improvement of limb ischemia after ACT as assessed by $\mathrm{TcPO}_{2}$ values. However, no significant improvement of any of the followed scintigraphic parameters at rest or during stress before or after ACT was observed. We did not find any correlation between these parameters if using $\mathrm{TcPO}_{2}$ measurement.

$\mathrm{TcPO}_{2}$ measurement still remains the gold standard of non-invasive evaluation of limb ischemia and assessment of the effect of revascularization, especially in diabetic patients with CLI, where ABPI is not a reliable tool because of medial sclerosis (Dubsky et al. 2014). $\mathrm{TcPO}_{2}$ serves as the main parameter for evaluating the therapeutic effect in studies focused on cell therapy in CLI patients by measuring local tissue perfusion and skin oxygenation (Fadini et al. 2010, Lawall et al. 2010, Liu et al. 2015).

An explanation for the discrepancy between 
$\mathrm{TcPO}_{2}$ values and assessed scintigraphic parameters is that $\mathrm{TcPO}_{2}$ reflects microcirculation status including local tissue perfusion and skin oxygenation (Benitez et al. 2014) in contrast to perfusion scintigraphy that counts muscle metabolic activity on the cellular level. Another factor potentially contributing to the differences between $\mathrm{TcPO}_{2}$ and ${ }^{99 \mathrm{~m}}$ Tc-MIBI could be selection of measurement sites.

Sayman and Urgancioglu (1991) demonstrated the diagnostic value of ${ }^{99 m}$ Tc-MIBI in patients with leg claudication. They successively performed muscle perfusion scans in 6 healthy controls and 18 patients with claudication pain at rest and after exercise on the same day. The authors observed symmetrical perfusion of both legs in the control group in contrast to uptake differences between two sides in PAD patients. The abnormalities of perfusion muscle scans were consistent with clinical findings. On the other hand, our study did not document any asymmetry in the assessed scintigraphic parameters between treated and untreated limbs before and after ACT. In contrast to the above study, all patients included in our study had diabetes with advanced micro- and macrovascular complications; unlike patients without diabetes, most of them were characterized by the absence of pain or claudication due to diabetic neuropathy and primarily infrapopliteal lesions (Jude et al. 2010).

Another study (Kusmierek et al. 2006) investigated regional blood supply of thigh and calf muscles using ${ }^{99 \mathrm{~m}}$ Tc-MIBI in the early stages of Dopplerdocumented atherosclerosis in patients without clinical symptoms of CLI as compared to healthy controls. Patients showing early atherosclerotic changes had significantly lower rest and stress perfusion indices of thighs and calves and significantly higher asymmetry in stress perfusion of thighs and calves than healthy controls.

How to explain the physiological background influencing the results of perfusion scintigraphy with ${ }^{99 \mathrm{~m}}$ Tc-MIBI in ischemic calf and foot muscles? Mitochondrial ${ }^{99 \mathrm{~m}}$ Tc-MIBI uptake depends on many factors: endothelial dysfunction and myocyte metabolism abnormalities affect mitochondrial ${ }^{99 \mathrm{~m}}$ Tc-MIBI uptake through changes in their cell membrane potential (Matsuo et al. 2013). Previous studies have demonstrated that an acquired metabolic myopathy is present in patients with chronic lower limb hypoperfusion and the myopathy may persist a long time after revascularization (Brass and Hiatt 2000, Makris et al. 2007, Pipinos et al. 2008). Not only blood flow and oxygen delivery are the main factors that limit function in PAD patients but, also, the presence of a metabolic defect in oxygen utilization in ischemic skeletal muscle. Studies investigating muscle cell biochemistry showed that mitochondria in ischemic skeletal muscle have extensively damaged DNA, altered enzyme activities, compromised mitochondrial respiration and impaired oxidative energy production (Pipinos et al. 2008). Mitochondrial ${ }^{99 \mathrm{~m}}$ Tc-MIBI uptake may be influenced by metabolic processes other than ischemia such as calf muscle activity and thickness. Diabetic peripheral neuropathy along with low physical activity leads to muscle atrophy. Another factor possibly affecting ${ }^{99 \mathrm{~m}}$ Tc-MIBI uptake is inflammation, very frequent in patients with diabetic foot.

Based on the results of our study, we assume that perfusion scintigraphy of calf muscles cannot furnish additional information about the functional consequences of cell therapy of CLI due to some factors. A major drawback is the difficulty to standardize the technique and to obtain exact and reproducible results over the same calf muscle region. A slightly altered position of the camera or patient impairs the quality of information. Another difficulty is increased variability due to technical issues such as clearance of background or intervals between phases of examinations. Another factor potentially affecting results of this examination is renal function as it determines the rate of blood clearance of Tc activity. Last but not least, perfusion scintigraphy is a time-consuming technique requiring good cooperation of the part of the patient often incapable of exercising adequately. Finally, there is also an issue with the assessment in patients with major amputation in the contralateral foot due to the absence of the control limb.

The discrepancy between myocardial perfusion scintigraphy that is widely used in the clinical setting and provides a quantitative assessment of myocardial function on the one hand, and perfusion scintigraphy of calf and foot muscles in the assessment of limb ischemia on the other could also be explained by differences in muscle structure as skeletal muscle has a substantially smaller number of mitochondria as compared with the myocardium. Moreover, previous studies have demonstrated that skeletal muscle myopathy in diabetic patients with PAD resulting in reduced strength and function is due to defective mitochondria (Pipinos et al. 2008).

The limitations of our study are the relatively small number of assessed patients, lack of stress test standardization due to insufficient cooperation from 
diabetic patients with CLI and diabetic foot ulcers.

\section{Conclusions}

We did not prove a contribution of perfusion scintigraphy of calf and foot muscles to the assessment of the effect of ACT in patients with diabetic foot and CLI. Limitations of this examination include high variability or non-standardized exercising conditions and parameters for assessing perfusion scintigraphy of the ischemic limb in diabetic patients. Unlike $\mathrm{TcPO}_{2}$ measurement shown to provide satisfactory assessment of changes after revascularization procedures in diabetic patients, perfusion scintigraphy is mainly impacted by muscle metabolism depending on the number and function of mitochondria. Moreover, impaired muscle metabolism could persist longer after successful revascularization and therefore could lead to difficulties with interpretation of perfusion scintigraphy of calf muscles as a method for the assessment of ACT.

\section{Conflict of Interest}

There is no conflict of interest.

\section{Acknowledgements}

Supported by Charles University in Prague, project GAUK 16415 and by the Ministry of Health of the Czech Republic, grant no. 16-27262A and by project for Development of Research Organization 00023001 (IKEM, Prague, Czech Republic) - Institutional support.

\section{References}

AGHI M, CHIOCCA EA: Contribution of bone marrow-derived cells to blood vessels in ischemic tissues and tumors. Mol Ther 12: 994-1005, 2005.

AI M, YAN CF, XIA FC, ZHOU SL, HE J, LI CP: Safety and efficacy of cell-based therapy on critical limb ischemia: a meta-analysis. Cytotherapy 18: 712-724, 2016.

BENITEZ E, SUMPIO BJ, CHIN J, SUMPIO BE: Contemporary assessment of foot perfusion in patients with critical limb ischemia. Semin Vasc Surg 27: 3-15, 2014.

BRASS EP, HIATT WR: Acquired skeletal muscle metabolic myopathy in atherosclerotic peripheral arterial disease. Vasc Med 5: 55-59, 2000.

BROWNRIGG JR, SCHAPER NC, HINCHLIFFE RJ: Diagnosis and assessment of peripheral arterial disease in the diabetic foot. Diabet Med 32: 738-747, 2015.

CELEN YZ, ZINCIRKESER S, AKDEMIR I, YILMAZ M: Investigation of perfusion reserve using 99Tc(m)-MIBI in the lower limbs of diabetic patients. Nucl Med Commun 21: 817-822, 2000.

COLLINSON DJ, DONNELLY R: Therapeutic angiogenesis in peripheral arterial disease: can biotechnology produce an effective collateral circulation? Eur J Vasc Endovasc Surg 28: 9-23, 2004.

COMPAGNA R, AMATO B, MASSA S, AMATO M, GRANDE R, BUTRICO L, DE FRANCISCIS S, SERRA R: Cell therapy in patients with critical limb ischemia. Stem Cells Int 2015: 931420, 2015.

DUA A, LEE CJ: Epidemiology of peripheral arterial disease and critical limb ischemia. Tech Vasc Interv Radiol 19: 91-95, 2016.

DUBSKY M, JIRKOVSKA A, BEM R, FEJFAROVA V, PAGACOVA L, SIXTA B, VARGA M, LANGKRAMER S, SYKOVA E, JUDE EB: Both autologous bone marrow mononuclear cell and peripheral blood progenitor cell therapies similarly improve ischaemia in patients with diabetic foot in comparison with control treatment. Diabetes Metab Res Rev 29: 369-376, 2013.

DUBSKY M, JIRKOVSKA A, BEM R, FEJFAROVA V, VARGA M, KOLESAR L, PAGACOVA L, SYKOVA E, JUDE EB: Role of serum levels of angiogenic cytokines in assessment of angiogenesis after stem cell therapy of diabetic patients with critical limb ischemia. Cell Transplant 23: 1517-1523, 2014.

FADINI GP, AGOSTINI C, AVOGARO A: Autologous stem cell therapy for peripheral arterial disease meta-analysis and systematic review of the literature. Atherosclerosis 209: 10-17, 2010.

GAEMPERLI O: New insights from major prospective cohort studies with cardiac nuclear imaging. Curr Cardiol Rep 16: 482, 2014. 
GRAZIANI L, SILVESTRO A, BERTONE V, MANARA E, ANDREINI R, SIGALA A, MINGARDI R, DE GIGLIO $\mathrm{R}$ : Vascular involvement in diabetic subjects with ischemic foot ulcer: a new morphologic categorization of disease severity. Eur J Vasc Endovasc Surg 33: 453-460, 2007.

GROPLER RJ, BEANLANDS RS, DILSIZIAN V, LEWANDOWSKI ED, VILLANUEVA FS, ZIADI MC: Imaging myocardial metabolic remodeling. J Nucl Med 51 (Suppl 1): 88S-101S, 2010.

HINCHLIFFE RJ, BROWNRIGG JR, APELQVIST J, BOYKO EJ, FITRIDGE R, MILLS JL, REEKERS J, SHEARMAN CP, ZIERLER RE, SCHAPER NC; INTERNATIONAL WORKING GROUP ON THE DIABETIC: IWGDF guidance on the diagnosis, prognosis and management of peripheral artery disease in patients with foot ulcers in diabetes. Diabetes Metab Res Rev 32 (Suppl 1): 37-44, 2016.

JUDE EB, ELEFTHERIADOU I, TENTOLOURIS N: Peripheral arterial disease in diabetes - a review. Diabet Med 27: 4-14, 2010.

KUSMIEREK J, DABROWSKI J, BIENKIEWICZ M, SZUMINSKI R, PLACHCINSKA A: Radionuclide assessment of lower limb perfusion using 99mTc-MIBI in early stages of atherosclerosis. Nucl Med Rev Cent East Eur 9: 18-23, 2006.

LAWALL H, BRAMLAGE P, AMANN B: Stem cell and progenitor cell therapy in peripheral artery disease. A critical appraisal. Thromb Haemost 103: 696-709, 2010.

LI Y, LI Q, LIANG S, LIANG X, ZHOU W, HE H, JIN R, WANG K, ZHU Z, YAN Z: A novel use of hill function and utility of $99 \mathrm{mTc}-\mathrm{MIBI}$ scintigraphy to detect earlier lower extremity microvascular perfusion in patients with type 2 diabetes. Medicine (Baltimore) 96: e8038, 2017.

LIU Y, XU Y, FANG F, ZHANG J, GUO L, WENG Z: Therapeutic efficacy of stem cell-based therapy in peripheral arterial disease: a meta-analysis. PLoS One 10: e0125032, 2015.

MAKRIS KI, NELLA AA, ZHU Z, SWANSON SA, CASALE GP, GUTTI TL, JUDGE AR, PIPINOS II: Mitochondriopathy of peripheral arterial disease. Vascular 15: 336-343, 2007.

MATSUO S, NAKAJIMA K, KINUYA S: Evaluation of cardiac mitochondrial function by a nuclear imaging technique using technetium-99m-MIBI uptake kinetics. Asia Ocean J Nucl Med Biol 1: 39-43, 2013.

NORGREN L, HIATT WR, DORMANDY JA, NEHLER MR, HARRIS KA, FOWKES FG, GROUP TIW, BELL K, CAPORUSSO J, DURAND-ZALESKI I, KOMORI K, LAMMER J, LIAPIS C, NOVO S, RAZAVI M, ROBBS J, SCHAPER N, SHIGEMATSU H, SAPOVAL M, WHITE C, WHITE J, CLEMENT D, CREAGER M, JAFF M, MOHLER E 3RD, RUTHERFORD RB, SHEEHAN P, SILLESEN H, ROSENFIELD K: Intersociety consensus for the management of peripheral arterial disease (TASC II). Eur J Vasc Endovasc Surg 33 (Suppl 1): S1-S75, 2007.

PIPINOS II, JUDGE AR, SELSBY JT, ZHU Z, SWANSON SA, NELLA AA, DODD SL: The myopathy of peripheral arterial occlusive disease: Part 2. Oxidative stress, neuropathy, and shift in muscle fiber type. Vasc Endovascular Surg 42: 101-112, 2008.

POMPOSELLI F: Arterial imaging in patients with lower extremity ischemia and diabetes mellitus. J Vasc Surg 52 (3 Suppl): 81S-91S, 2010.

POTIER L, ABI KHALIL C, MOHAMMEDI K, ROUSSEL R: Use and utility of ankle brachial index in patients with diabetes. Eur J Vasc Endovasc Surg 41: 110-116, 2011.

SAYMAN HB, URGANCIOGLU I: Muscle perfusion with technetium-MIBI in lower extremity peripheral arterial diseases. J Nucl Med 32: 1700-1703, 1991.

SUN X, YING J, WANG Y, LI W, WU Y, YAO B, LIU Y, GAO H, ZHANG X: Meta-analysis on autologous stem cell transplantation in the treatment of limb ischemic. Int J Clin Exp Med 8: 8740-8748, 2015.

UNDERWOOD SR, ANAGNOSTOPOULOS C, CERQUEIRA M, ELL PJ, FLINT EJ, HARBINSON M, KELION AD, AL-MOHAMMAD A, PRVULOVICH EM, SHAW LJ, TWEDDEL AC; BRITISH CARDIAC SOCIETY; BRITISH NUCLEAR CARDIOLOGY SOCIETY, BRITISH NUCLEAR MEDICINE SOCIETY, ROYAL COLLEGE OF PHYSICIANS OF LONDON; ROYAL COLLEGE OF RADIOLOGISTS: Myocardial perfusion scintigraphy: the evidence. Eur J Nucl Med Mol Imaging 31: 261-291, 2004.

WOLFRAM RM, BUDINSKY AC, SINZINGER H: Assessment of peripheral arterial vascular disease with radionuclide techniques. Semin Nucl Med 31: 129-142, 2001. 